\title{
A Case of Mixed Epithelial and Mesenchymal Hamartoma of Nasopharynx
}

\author{
Kyoung Min Kim, Sam Hyun Kwon ${ }^{2}$, Ho Sung Park ${ }^{1}$ and Myoung Jae Kang ${ }^{1}$ \\ ${ }^{1}$ Departments of Pathology, ${ }^{2}$ Otorhinolaryngology-Head and Neck Surgery, Institute for Medical Sciences, \\ Research Institute of Clinical Medicine, Chonbuk National University Medical School, \\ Chonbuk National University Hospital, Jeonju, Korea
}

\section{비인두에서 발견된 상피·중간엽성 과오종 1예}

김경민 ${ }^{1} \cdot$ 권삼현 ${ }^{2} \cdot$ 박호성 ${ }^{1} \cdot$ 강명재 $^{1}$

전북대학교 의학전문대학원 전북대학교병원 의과학연구소, 임상의학연구소, 병리학교실, ${ }^{1}$ 이비인후과학교실 ${ }^{2}$

Received November 28, 2011

Revised February 1, 2012

Accepted February 13, 2012

Address for correspondence

Myoung Jae Kang, MD

Department of Pathology,

Chonbuk National University

Medical School,

Chonbuk National University

Hospital, San 2-20 Geumam-dong,

Deokjin-gu, Jeonju 561-180, Korea

Tel $+82-63-250-2262$

Fax $+82-63-250-1229$

E-mail rock52@hanmail.net
Mixed epithelial and mesenchymal hamartoma in the nasopharynx is extremely rare. Hamartomas of the nasal cavity or nasopharynx are classified as epithelial, mesenchymal and mixed epithelial and mesenchymal types. We report an incidentally detected lesion arising in a 42-year-old female patient. The mass was resected endoscopically and was diagnosed as mixed epithelial and mesenchymal hamartoma. We report and discuss the pathological features and differential diagnosis of this rare nasopharyngeal hamartoma.

Korean J Otorhinolaryngol-Head Neck Surg 2012;55:191-3

Key Words Hamartoma $\cdot$ Epithelial $\cdot$ Mesenchymal $\cdot$ Nasopharynx.

\section{Introduction}

Hamartomas are non-malignant malformation or inborn errors of tissue development characterized by haphazard arrangement and growth of tissue indigenous to the specific part of the body where they present. ${ }^{1}$ They commonly originate from the lung, kidney and intestine. ${ }^{2)}$ However, hamartomas in the nasal cavity or nasopharynx are quite rare. Hamartomas of the nasal cavity or nasopharynx are classified as epithelial, mesenchymal and mixed epithelial and mesenchymal types. Respiratory epithelial adenomatoid hamartoma is subtype of epithelial type hamartoma, which is the most common hamartoma of these lesions. ${ }^{3)}$ Mixed epithelial and mesenchymal hamartoma is much rarer than epithelial type. We present a rare case of a mixed epithelial and mesenchymal hamartoma in the nasopharynx.

\section{Case}

A 42-year-old woman presented with incidentally detected nasopharyngeal mass. She visited local clinic for upper respiratory infectious symptoms. And at there the mass was detected by endoscope examination and she was referred to our hospital. Physical examination revealed pink elevated lesion with stalk at right side of the nasopharynx. Her prior medical history was unremarkable. The laboratory data were normal. Computed tomography scan could not find any abnormal mucosal thickening or soft tissue density at paranasal sinus or nasal cavity. And also bone erosion or destruction were not identified (Fig. 1). But by the endoscopic evaluation the mass was obviously visible. And the possibility of malignant tumor, such as nasopharyngeal carcinoma, could not be ruled out. Therefore local excision through nasal endoscope 
was performed under general anesthesia. During the surgery another mass at the posterior nasal septum was detected.

Macroscopically the resected nasopharyngeal and posterior nasal septal masses were $0.8 \mathrm{~cm}$ and $1.8 \mathrm{~cm}$ in largest diameter, respectively. Both masses were relatively firm. The cut surface showed intermixed grayish and yellowish tissue. Microscopic findings of nasopharyngeal and posterior septal masses were similar. The mass was covered with respiratory epithelium. The stroma was composed of mixture of fibrous and mature adipose tissue. The fibrous tissue contained proliferating glandular structures most of which were composed of exclusively small seromucinous glands with minimal amount of cystically dilated structures lined by low cuboidal to flat epithelium. These proliferating glands were arranged in clusters, lobules, or haphazard pattern. And small foci of proliferating neural tissue and infiltration of lymphocytes were present (Fig. 2). Both masses were consistent with mixed epithelial and mesenchymal hamartoma.

\section{Discussion}

Hamartomas are incapable of continuous unimpeded growth

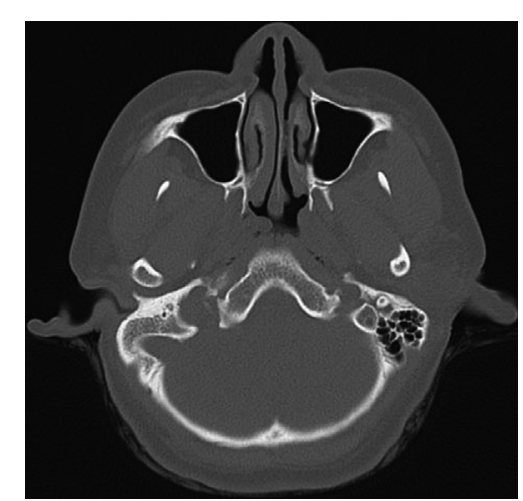

Fig. 1. Computed tomography scan could not find any abnormal mucosal thickening or soft tissue density at paranasal sinus or nasal cavity. And also bone erosion or destruction was not identified. and so their proliferation is self-limiting; however, they have no tendency to spontaneous regression. ${ }^{1)}$ Also, it has been speculated that they arise as a result of an underlying inflammatory process. ${ }^{4)}$

Presenting symptoms of nasopharyngeal hamartomas are typically vague and nonspecific. The most common clinical complaints are nasal obstruction and/or epistaxis. ${ }^{3)}$ Our patient had no obstructive symptoms or epistaxis. But was incidentally detected during endoscopic examination due to patient's upper respiratory infections symptoms.

The treatment of choice for nasopharyngeal hamartoma is complete surgical removal of the hamartoma as incomplete treatment leaves the risk of recurrence. ${ }^{1)}$ Although, because the limited growth potential of a hamartoma, local recurrence is very rare. Local resection through endoscopic sinus surgery is recommended if the lesion is confined to the nasal cavity or nasopharynx because of its relatively limited morbidity. ${ }^{2)}$ Adjuvant therapy is unnecessary, making correct diagnosis imperative to avoid potential harmful effects to the patient. ${ }^{5)}$ The present patient underwent resection of the mass endoscopically, and had no adjuvant therapy. And until present, there was no recurrence.

Hamartomas in the nose and the nasopharynx may be predominantly composed of mesenchymal or epithelial tissues. ${ }^{3)}$ The mesenchymal hamartomas have been named chondroid, chondromesenchymal, angiomatous, or lipomatous, depending on the preponderant tissue. ${ }^{6}$ ) The subtypes of epithelial hamartomas are respiratory epithelial adenomatoid hamartoma and seromucinous hamartoma. ${ }^{6)}$ Respiratory epithelial adenomatoid hamartoma being the most common and second and much rarer type is the seromucinous hamartoma. ${ }^{7)}$ Hamartomas showing a mixture of mesenchymal and epithelial elements have also been reported. ${ }^{5,8)}$

Seromucinous hamartoma was first described by Baillie and Batsakis $^{7)}$ in 1974. The lesions subsequently reported (with
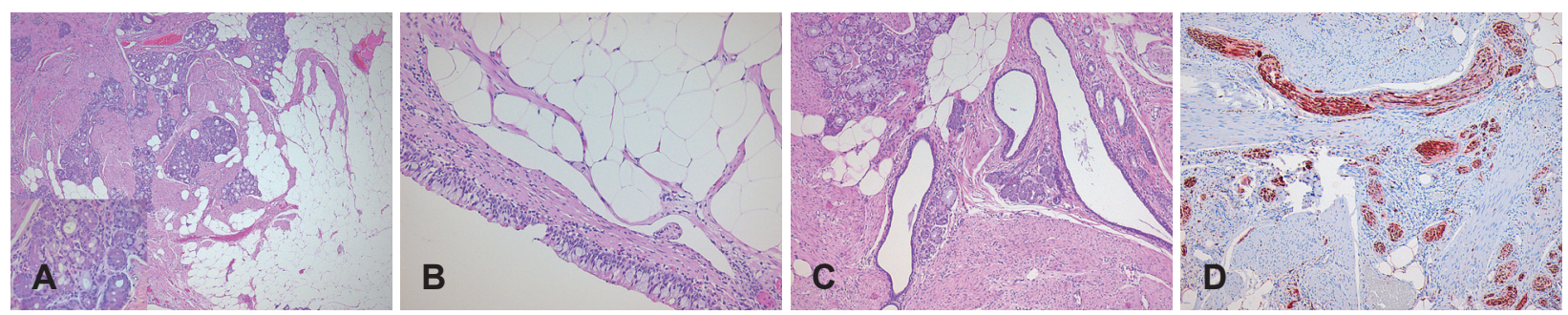

Fig. 2. Histologic and immunohistochemical features of mixed epithelial and mesenchymal hamartoma of nasopharynx. Low-power field $(H \& E$ stain, $\times 40)$ revealed that the mass was composed of fibrous tissue containing glands and mature adipose tissue. Almost all the glandular components were composed of exclusively small seromucinous glands arranged in clusters, lobules, or haphazard pattern, which are shown at higher magnification $(H \& E$ stain, $\times 400)$ in the inset bottom left $(A)$. Tall columnar and goblet cells lining the surface of the mass $(H \& E$ stain, $\times 100)(B)$. Minimal amount of cystically dilated structures lined by low cuboidal to flat epithelium $(H \& E$ stain, $\times 100)(C)$. Small focus of proliferating nervous tissue showing strong immunoreactivity for S-100 protein (D). 
varying nomenclature) by Zarbo and McClatchey, ${ }^{9)}$ GraemeCook and Pilch, ${ }^{3)}$ Chuang and Lin, ${ }^{10)}$ Weinreb, et al. ${ }^{11)}$ and Ambrosini-Spaltro, et al. ${ }^{12)}$

The histopathology of seromucinous hamartoma that has been reported to the date was similar and those findings were: 1) polypoid masses covered by ciliated respiratory epithelium; 2) stroma varied from edematous to fibrous and contained a variable combination of invaginated respiratory epithelium forming glands and cysts, cysts lined by low cuboidal to flat epithelium, and a proliferation of small serous glands in variable proportions; 3) glandular components consisted of small glands, ducts and tubules with lobular and irregular haphazard patterns; 4) occasionally periglandular stromal hyalinization; and 5) moderate chronic inflammation predominantly composed of small lymphocytes and plasma cells. ${ }^{12)}$ According to the above findings, epithelial component of this case was consistent with that of seromucinous hamartomas.

But in present case, not only proliferating epithelial component, but mesenchymal component including proliferating mature adipose tissue were present. Also, a few small but obvious foci of proliferating nervous tissue was also identified. These microscopic findings are indicative of mixed epithelial and mesenchymal hamartoma. To the date, the reports of nasopharyngeal mixed epithelial and mesenchymal hamartomas are very rare. ${ }^{5,8)}$ Furthermore epithelial component of all reported mixed epithelial and mesenchymal hamartomas showed characteristics of respiratory epithelial adenomatoid hamartoma. And mesenchymal components were composed of chondroid and/or osseous tissues. ${ }^{5,8)}$ To our best knowledge this is the first reporting case of nasopharyngeal hamartoma composed of mixed seromucinous epithelial and almost purely lipomatous mesenchymal component.

From a practical perspective, the most significant differential diagnosis of seromucinous hamartoma is low-grade sinonasal adenocarcinoma (LGSNA). ${ }^{13)}$ The hamartomas usually occur in nasal cavity, particulary posterior nasal septum, other sites include nasopharynx, ethmoid sinus, and frontal sinus. LGSNA may occur at any site but predilect to nasal cavity and ethmoid sinus. Most common symptoms of hamartoma and LGSNA are nasal obstruction and epistaxis. Because of similar occurring sites and presenting symptoms, it can be difficult to distinguish hamartoma from LGSNA.

Also, the histopathology of both LGSNAs and seromucinous hamartomas show small glands and bland cytological features. Notwithstanding these similarities, seromucinous hamartoma and LGSNA have significant clinical and archi- tectural differences. The presence of a residual lobular architecture with variable chronic inflammation, and absence of epithelial tufting and papillae, 'back-to-back' glands with true cribriform pattern, trabecular pattern, or invasion of normal structures favour a diagnosis of seromucinous hamartoma. It must be remembered that the lack of a myoepithelial layer in the small glands of seromucinous hamartomas is a potential diagnostic pitfall, which may prompt an erroneous diagnosis of LGSNA. Laminin may be useful in the differential diagnosis because it highlights the lobular architecture of hamartomas with clustered glands resembling a 'back-to-back' pattern. ${ }^{11,13)}$

The seromucinous glands of these hamartomas lack a myoepithelial layer, thus superficially resembling other uncommon benign small gland proliferations such as microglandular adenosis of the breast. ${ }^{12)}$ Awareness of the clinical and pathological features of these lesions is necessary to avoid an unwarranted diagnosis of LGSNA.

\section{REFERENCES}

1) Owens D, Alderson D, Garrido C. Nasopharyngeal hamartoma: importance of routine complete nasal examination. J Laryngol Otol 2004;118(7):558-60.

2) Metselaar RM, Stel HV, van der Baan S. Respiratory epithelial adenomatoid hamartoma in the nasopharynx. J Laryngol Otol 2005; 119(6):476-8

3) Graeme-Cook F, Pilch BZ. Hamartomas of the nose and nasopharynx. Head Neck 1992;14(4):321-7.

4) Endo R, Matsuda H, Takahashi M, Hara M, Inaba H, Tsukuda M. Respiratory epithelial adenomatoid hamartoma in the nasal cavity. Acta Otolaryngol 2002;122(4):398-400.

5) Flavin R, Russell J, Phelan E, McDermott MB. Chondro-osseous respiratory epithelial adenomatoid hamartoma of the nasal cavity: a case report. Int J Pediatr Otorhinolaryngol 2005;69(1):87-91.

6) Park SK, Jung H, Yang YI. Mesenchymal hamartoma in nasopharynx: a case report. Auris Nasus Larynx 2008;35(3):437-9.

7) Baillie EE, Batsakis JG. Glandular (seromucinous) hamartoma of the nasopharynx. Oral Surg Oral Med Oral Pathol 1974;38(5):760-2.

8) Wenig BM, Heffner DK. Respiratory epithelial adenomatoid hamartomas of the sinonasal tract and nasopharynx: a clinicopathologic study of 31 cases. Ann Otol Rhinol Laryngol 1995;104(8):639-45.

9) Zarbo RJ, McClatchey KD. Nasopharyngeal hamartoma: report of a case and review of the literature. Laryngoscope 1983;93(4):494-7.

10) Chuang SS, Lin CN. Microglandular adenosis arising in chronic paranasal sinusitis. Histopathology 2000;36(4):376-7.

11) Weinreb I, Gnepp DR, Laver NM, Hoschar AP, Hunt JL, Seethala RR, et al. Seromucinous hamartomas: a clinicopathological study of a sinonasal glandular lesion lacking myoepithelial cells. Histopathology 2009;54(2):205-13.

12) Ambrosini-Spaltro A, Morandi L, Spagnolo DV, Cavazza A, Brisigotti M, Damiani S, et al. Nasal seromucinous hamartoma (microglandular adenosis of the nose): a morphological and molecular study of five cases. Virchows Arch 2010;457(6):727-34.

13) Neto AG, Pineda-Daboin K, Luna MA. Sinonasal tract seromucous adenocarcinomas: a report of 12 cases. Ann Diagn Pathol 2003;7(3): $154-9$. 